\title{
Evaluation and Prediction of the HIV-1 Central Polypurine Tract Influence on Foamy Viral Vectors to Transduce Dividing and Growth-Arrested Cells
}

\author{
Sergey Shityakov, ${ }^{1}$ Carola Förster, ${ }^{1}$ Axel Rethwilm, ${ }^{2}$ and Thomas Dandekar ${ }^{3}$ \\ ${ }^{1}$ Department of Anesthesia and Critical Care, University of Würzburg, 97080 Würzburg, Germany \\ ${ }^{2}$ Department of Virology, University of Würzburg, 97074 Würzburg, Germany \\ ${ }^{3}$ Department of Bioinformatics, University of Würzburg, 97074 Würzburg, Germany \\ Correspondence should be addressed to Sergey Shityakov; shityakoff@mail.ru
}

Received 25 November 2013; Accepted 18 February 2014; Published 9 June 2014

Academic Editors: E. Carrillo and E. Martinez

Copyright ( 2014 Sergey Shityakov et al. This is an open access article distributed under the Creative Commons Attribution License, which permits unrestricted use, distribution, and reproduction in any medium, provided the original work is properly cited.

\begin{abstract}
Retroviral vectors are potent tools for gene delivery and various biomedical applications. To accomplish a gene transfer task successfully, retroviral vectors must effectively transduce diverse cell cultures at different phases of a cell cycle. However, very promising retroviral vectors based on the foamy viral (FV) backbone lack the capacity to efficiently transduce quiescent cells. It is hypothesized that this phenomenon might be explained as the inability of foamy viruses to form a pre-integration complex (PIC) with nuclear import activity in growth-arrested cells, which is the characteristic for lentiviruses (HIV-1). In this process, the HIV-1 central polypurine tract (cPPT) serves as a primer for plus-strand synthesis to produce a "flap" element and is believed to be crucial for the subsequent double-stranded cDNA formation of all retroviral RNA genomes. In this study, the effects of the lentiviral cPPT element on the FV transduction potential in dividing and growth-arrested $\left(\mathrm{G}_{1} / \mathrm{S}\right.$ phase) adenocarcinomic human alveolar basal epithelial (A549) cells are investigated by experimental and theoretical methods. The results indicated that the HIV-1 cPPT element in a foamy viral vector background will lead to a significant reduction of the FV transduction and viral titre in growth-arrested cells due to the absence of PICs with nuclear import activity.
\end{abstract}

\section{Introduction}

Retroviral vectors are efficient gene transfer vehicles that deliver transgenes by integration of the viral genome into the genome of host cells. This remarkable ability has been widely exploited for many biomedical applications, including gene therapy. In order to replicate, all retroviruses pursue a very complex process, which is known as reverse transcription. During this event, they transcribe their single-stranded RNA genomes into double-stranded complementary DNA (ds cDNA) prior to its integration into the host genome $[1,2]$. The outcome of reverse transcription is a linear DNA with long terminal repeats (LTRs) at the $3^{\prime}$ and $5^{\prime}$ ends of the viral genome. As an example, lentiviruses (HIV-1) have evolved into new forms with a complex reverse transcription strategy including a strand displacement event controlled by the central polypurine tract (cPPT), which serves for plus-strand initiation and priming $[3,4]$.
The HIV-1 reverse transcription produces a linear DNA molecule bearing a "peculiar formation," known as the central DNA flap element, because the reverse transcription complex stops at the central termination sequence (CTS) (Figure 1(a)). This flap element is believed to be essential for a preintegration complex (PIC) assembly, which is composed of both viral and cellular proteins [5-7] and possess the ability to cross the nuclear pore to enter the nucleus. It was previously reported that some constituents of PIC, such as the viral matrix protein, contained a nuclear localization signal (NLS) for PIC-mediated nuclear import $[8,9]$. However, the detailed mechanisms of this process are not yet fully elucidated.

The other retroviruses, such as foamy viruses (FV), have a replication strategy and probably a PIC formation mechanism different from that present in lentiviruses. FVs belong to the Spumavirinae retroviral subfamily and are known as nonpathogenic retroviral species, which are endemic to 


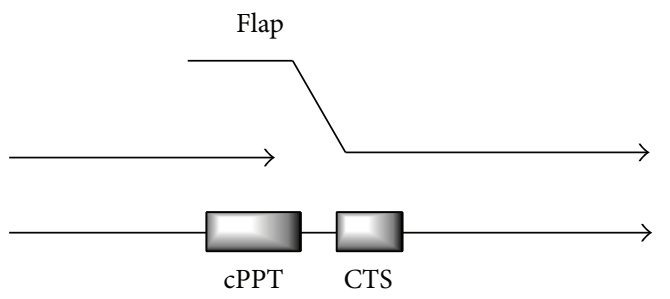

(a)

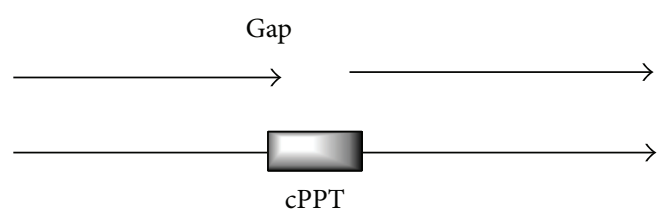

(b)

FIGURE 1: Different reverse transcription outcomes in lenti- (a) and foamy viruses (b). cPPT and CTS abbreviations stand for the central polypurine tract and central termination sequence, respectively.

a number of mammalians such as non-human primates, cats, and cows [10].

The genomic organization of the FVs, including the prototype foamy virus (PFV), which is a molecular cloned simian foamy virus $\operatorname{SFVcpz}(\mathrm{hu})$, is similar to that of other complex retroviruses, with several additional open reading frames located in $3^{\prime}$ of the canonical Gag, Pol, and Env genes, including the transcriptional transactivator gene (tas) [11-15].

The foamy viruses have a very broad host range and infect a variety of cell lines, including fibroblastoid, epithelioid, and lymphatic lineages [16]. There are currently a few cell lines that are resistant to FV infection, such as the zebrafish PAC2 and human erythroid precursor cell lines [17]. FV infection leads to massive cell death via apoptosis in vitro and without any overt pathogenic effect in vivo [18].

Essentially, foamy viruses seem to have diverse outcomes for the plus-strand priming events in contrast to lentiviruses. In FV reverse transcription, the strong stop plus-strand DNA is displaced by DNA elongating from cPPT. This DNA can further be transferred to the $3^{\prime}$ end of the minus-strand DNA or serve as a template for synthesis of a double-stranded LTR. Consequently, cPPT is degraded after completion of the minus-strand cDNA synthesis producing a single-stranded gap (Figure 1(b)) [19-21].

There are a number of FV-based vectors for gene therapy that have been developed [22-24]. These constructs have several desirable properties in comparison to lentiviral vectors. The main characteristics of foamy viral vectors are (i) safety: FVs have not been linked to any established pathology [18, 25]; (ii) wide tissue tropism [10, 26-28]; (iii) viral particles stable and resilient to ultracentrifugation [29]; (iv) packaging efficacy for foreign DNA that is at least $9 \mathrm{~kb}$ and offers a valuable tool for the transfer of long genetic elements and therapeutic transgenes [30]; (v) potential for production of high-titre FV vectors suitable for ex vivo gene therapy applications [24, 30, 31].

However, these very promising foamy viral vectors have one limitation in their ability to efficiently transduce terminally differentiated and growth-arrested mammalian cells [32] potentially because of their mitosis-dependent integration [22] and the deficiency in forming PICs with nuclear import activity from the absence of the lentivaral cPPT element and central termination sequence.

Therefore, the role of HIV-1 cPPT on FV replication and its mechanism of action is still to be determined. To pursue this goal, the transduction rates of cPPT (HIV-)modified $\mathrm{FV}$ vectors in dividing and growth-arrested adenocarcinomic human alveolar basal epithelial (A549) cells were accessed along the investigation of underlying molecular mechanisms and evaluation of their potential for FV-based gene therapy.

\section{Materials and Methods}

Recombinant DNA techniques: standard molecular cloning techniques were used for the generation of constructs [33]. A series of plasmid cloning vectors were preceded by the letter "p". In brief, the pUC19-based intermediate was first generated by ligating a $1.259 \mathrm{~kb}$ EcoRI-KpnI fragment from pMD9 $(9.940 \mathrm{~kb})$ with a $2.674 \mathrm{~kb}$ EcoRI-KpnI fragment from the pUC19 vector to use the proper restriction sites. Then, four pUC19-based plasmids, such as pUC19-cPPT (HIV)-CTS, pUC19-cPPT (PFV)-CTS, pUC19-cPPT (HIV), and pUC19CTS, were generated by PCR amplification and insertion of the fragments bearing the viral structural elements (Table 1) using relevant oligonucleotides (Table 2) with MfeI-StuI restriction sites. The lentiviral pWPXL vector $(10.510 \mathrm{~kb})$ was used as a template for the cPPT (HIV), cPPT (HIV)-CTS, and CTS amplifications. All pMD9-based FV vectors contained the gene encoding enhanced green fluorescent protein (eGFP) under the control of a constitutively active heterologous retroviral U3 promoter to enable the quantification of vector transfer rates (Figure 2).

Cell transfection and purification of supernatant: human embryonic kidney (HEK 293T) cells [34] were seeded in $2 \times$ $10^{6}$ density into $6 \mathrm{~cm}$ dishes a day before the transfection. The cells were transfected with plasmid DNA using a polyethyleneimine transfection reagent (Polysciences Europe GmbH, Eppelheim, Germany) [35]. The PFV transfection mixture contained $2.5 \mu \mathrm{g}$ of modified pMD9 vectors, $1.25 \mu \mathrm{g}$ of pCIgag2, $0.5 \mu \mathrm{g}$ of pCpol-2, and pCenv-1 packaging plasmids [35]. The HIV transfection system contained $2.5 \mu \mathrm{g}$ of pWPXL, $1.9 \mu \mathrm{g}$ of psPAX2, and $0.8 \mu \mathrm{g}$ of pMD2.G (VSV-G) vectors (gifts from Professor Didier Trono), respectively. The pMD9 plasmid without Env (pMD9-w/oEnv) and pcDNA (Invitrogen $\mathrm{GmbH}$, Karlsruhe, Germany) as an empty vector were used as negative controls without a production of viral particles. One day after transfection, the cellular transcription was induced by addition of $10 \mathrm{mM}$ sodium butyrate for $8 \mathrm{hrs}$ [36]. After two days, the supernatant was harvested, passed through a $0.45 \mu \mathrm{m}$ filter (Merck Millipore, Darmstadt, 
TABLE 1: Sequences of the viral structural elements used in the construction of modified expression vectors.

\begin{tabular}{lcl}
\hline Element & Length $(\mathrm{bp})$ & Sequence \\
\hline cPPT $($ PFV $)$ & 9 & AGGAGAGGG \\
cPPT $(\mathrm{HIV})$ & 33 & ATCCACAATTTTAAAAGAAAAGGGGGGATTGGG \\
CTS & 16 & AAAAATTCAAAATTTT \\
\hline
\end{tabular}

TABLE 2: Forward and reverse primers for a PCR amplification of the fragments used in the construction of modified expression vectors.

\begin{tabular}{ll}
\hline Fragments & Primers \\
\hline \multirow{2}{*}{ cPPT (PFV)-CTS } & $5^{\prime}$-TATACAATTGCAGGAGAGGGATTGGGGGGTACAGTGCAG-3' \\
\hline \multirow{2}{*}{ cPPT (HIV)-CTS } & $5^{\prime}$-TATAAGGCCTCTGTCCCTGTAATAAACC-3' \\
\hline \multirow{2}{*}{ cPPT (HIV) } & $5^{\prime}$-TATACAATTGATGGCAGTATCCAC-3' \\
& $5^{\prime}$-TATAAGGCCTCTGTCCCTGTAATAAACC-3' \\
\hline \multirow{2}{*}{ CTS } & $5^{\prime}$-TATACAATTGATGGCAGTATCCAC-3' $^{\prime}$ \\
& $5^{\prime}$-TATAAGGCCTGTAATTTGTTTTTGTATTCT-3' \\
\hline
\end{tabular}

Germany), and layered onto $6 \mathrm{~mL}$ of sucrose cushion $(20 \%$ in DMEM). The supernatant was centrifuged in a SureSpin 630 rotor (Thermo Scientific, Sorvall, Waltham, MA, USA) at 25000 r.p.m at $4^{\circ} \mathrm{C}$ for 3 hrs.

Cell transduction and cell cycle experiments: after clarification, the vector-containing supernatants from HEK 293T cells were functionally assayed to transduce the A549 cellline, which were incubated with them for two days at different conditions. The conditions were created in the experiment to test the generated pMD9-based plasmids to efficiently transduce dividing and nondividing cells $\left(G_{1} / S\right.$ phase of a cell cycle): in Dulbecco's modified Eagles medium (DMEM) as a control, in the presence of dimethyl sulfoxide (DMSO), and in the presence of aphidicolin (Figure 3). The drug was purchased from Sigma-Aldrich (Germany Sigma-Aldrich Chemie $\mathrm{GmbH}$, Germany) as a potent antiviral, antimitotic agent, and DNA polymerase inhibitor, which is used to stop a cell cycle at $G_{1} / S$ phase. The drug was dissolved in pure DMSO and added to cells at $5 \mu \mathrm{g} / \mathrm{mL}$ concentration for $24 \mathrm{hrs}$ [32]. The final concentration of DMSO was approximately $0.1 \%$ in the medium.

Immunoblotting of viral proteins: analysis of viral protein expression was done essentially as described elsewhere [37]. In brief, the lysates were prepared from the partially purified vector supernatant and from transfected cells by suspension in a detergent-containing buffer. Viral proteins were reacted with anti-Gag [23] and anti-Pol [38] mouse monoclonal antibodies (mAbs) after separation in 8\% SDS-PAGE and semidry blotting onto Hybond ECL membranes (Amersham Pharmacia Biotech, Freiburg, Germany). Protein bands were detected by using horseradish peroxidase-coupled secondary antibodies (Dako, Hamburg, Germany) and employing the enhanced chemiluminescence detection system (Amersham Pharmacia Biotech, Freiburg, Germany). The ImageJ software (National Institute of Health, Bethesda, MD, USA) was used to analyse quantitatively the immunoblotting results.
Vector transfer technique: after clarification, the vectorcontaining supernatants were also assayed functionally by transfer to $1.5 \times 10^{4}$ recipient A549 cells purchased from American Type Culture Collection (ATCC, Manassas, VA, USA). The expression of eGFP per $10^{4}$ cells was monitored by flow cytometry (FCM) for $48 \mathrm{hrs}$ after the transduction. The vector transfer assays were repeated at least three times.

Viral transduction dynamics and viral titre prediction: the MATLAB R2012a software (MathWorks, Natick, MA, USA) was used to predict the viral transduction dynamics $\left(f(x)_{\mathrm{td}}\right)$ and viral titre $\left(f(x)_{\mathrm{vt}}\right)$ for the analysed plasmids. Sigmoid dose-response logistic function was implemented in the MATLAB script M-files using the following equations:

$$
\begin{aligned}
f(x)_{\mathrm{td}} & =\frac{0.01 a}{0.01+e^{(-b x)}}, \\
f(x)_{\mathrm{vt}} & =\frac{a}{0.01+e^{x}},
\end{aligned}
$$

where $x$ is any independent variable described by linspace function; $a$ is a transduction rate (percentage of eGFP cells); $e$ is an exponential constant $(e=2.718)$; and $b$ integer is a Hill Slope. The linspace function $(x=\operatorname{linspace}(0,48))$ was used to generate linearly spaced vectors for 48-hour interval curve. The $b$ integer $(b=0.21)$ was adjusted to the $f(x)_{\mathrm{td}}$ logistic function for pWPXL $\left(y_{1}=1 . /(0.01+\exp (-x\right.$. * $0.21))$ ) as a reference curve reaching the upper plateau level with maximal effect after 48 hrs (Supplementary Material 1 in Supplementary Material available online at http://dx.doi .org/10.1155/2014/487969). To determine the viral titre dynamics, seven dilutions were inspected in the range from the highest $(0.1)$ to the lowest $\left(10^{-7}\right)$ concentrations of the virus $(x=$ linspace $(0,6))$. 


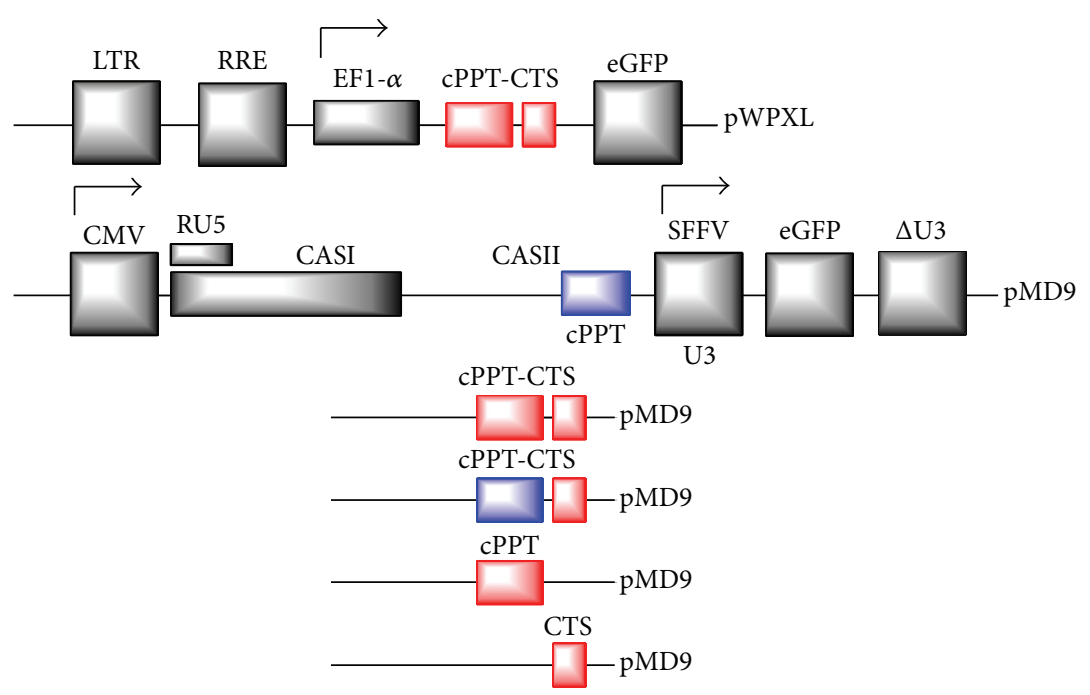

FIGURE 2: The structural elements of pWPXL and pMD9 parental plasmid backbones are shown: long terminal repeat (LTR) with U3, R, and U5 regions, ref-responsive element (RRE), human elongation factor alpha promoter (EF1- $\alpha$ ), gene encoding enhanced green fluorescent protein (eGFP), enhancer/promoter of the human cytomegalovirus immediate early gene (CMV), cis-acting sequences (CASI and CASII), constitutively active spleen focus forming virus U3 promoter (SFFV U3), and internally deleted U3 region of the $3^{\prime}$ LTR ( $\triangle$ U3). Foamy viral cPPT was replaced with cPPT (HIV) in different variations. CTS was deleted or inserted in accordance with the scheme shown above.

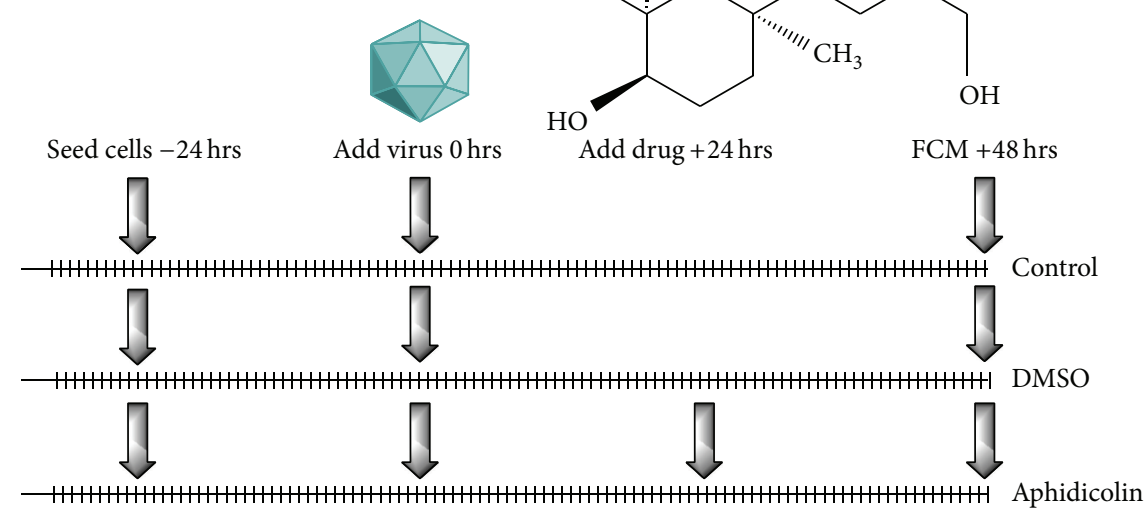

FIGURE 3: The timescale representation of the transduction experiments with aphidicolin substance to stop a cell cycle in $\mathrm{G}_{1} / \mathrm{S}$ phase. DMSO was added to the A549 cells for a toxicity evaluation and as a solvent for the drug.

\section{Results and Discussion}

To be functional, the retroviral system for gene therapy must comprise two principal elements, these being as truncated viral backbones and packaging plasmids. The PFV system therefore includes the Cas I and Cas II (cPPT) backbone elements as a part of pMD9 and pCIgag2, pCpol-2, and pCenv-1 packaging plasmids. On the contrary, the HIV system comprises the $\psi$ packaging signal, ref-responsive element (RRE), cPPT-CTS, and posttranscriptional cis-acting regulatory element (WPRE) as a part of the pWPXL vector together with psPAX2 (Gag, Pol, rev, and tat) and pMD2.G (VSV-G) packaging vectors to produce G-glycoprotein pseudotyped retroviral particles.
To address the question of the influence of cPPT (HIV) together with the CTS element on the foamy viral cycle, we compared the cell cycle requirements for efficient cell transduction by the pMD9- and pWPXL-based plasmids, expressing the same transgene (eGFP) under control of different promoters (SFFV U3 in pMD6 and EF1- $\alpha$ in pWPXL) in dividing and growth-arrested $\left(\mathrm{G}_{1} / \mathrm{S}\right)$ A549 cells. Although there are the previously published reports that have already focused on the cell cycle aspects of retroviral infection [39, 40], the investigation is the first direct attempt to assess the role of cPPT modifications for the two genera of viruses: lentiviruses (HIV-1) and spumaviruses (PFV).

The analysis of the viral transduction rates revealed that both untreated or DMSO-treated cells experienced minor 


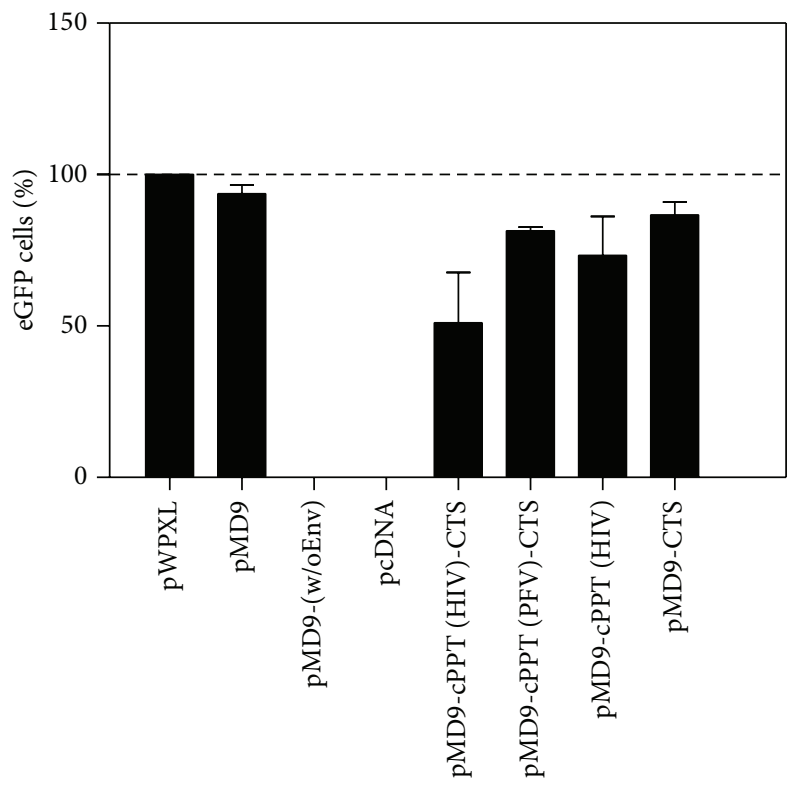

(a)

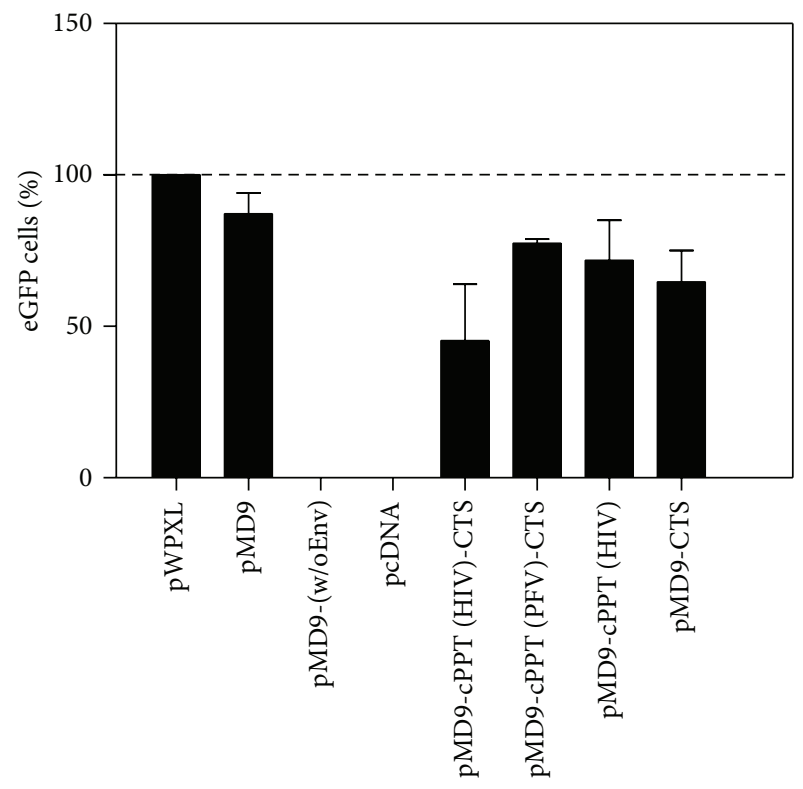

(b)

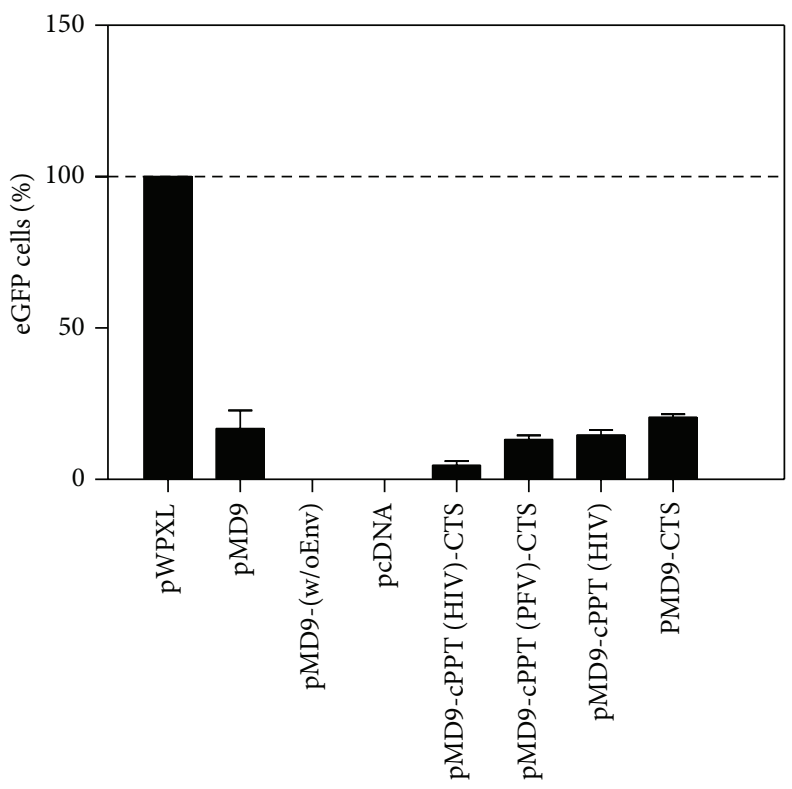

(c)

FIGURE 4: The summarized statistics of retroviral replication efficiency (transduction rate) in the A549 cells. The pMD9-based plasmids were tested to efficiently transduce dividing and growth-arrested cells $\left(G_{1} / S\right.$ phase of cell cycle). Three conditions were analysed in the experiment: control (a); DMSO (b); aphidicolin (c). The mean \pm SD values from three independent assays are shown.

decreases in transduction rates for the pMD9-based plasmids with different cPPT modifications in comparison to pMD9 and pWPXL controls (Figures 4(a) and 4(b)). These results indicated that the productive infection was observed only if target cells were allowed to pass through mitosis. On the other hand, there was a huge difference in the relative transduction efficiencies of the vectors when the cells were $G_{1} / S$-arrested for 24 hours after transduction; while the efficiency of pWPXL was approximately twenty- (pMD9-cPPT (HIV)CTS) to fivefold (pMD9-CTS) higher than that of the pMD9based vectors (Figure $4(\mathrm{c})$ ). The short inserts, such as CTS and cPPT (HIV), also displayed an insignificant reduction in the transduction rates observed in dividing cells. The longer insert (cPPT (HIV)-CTS) resulted in an almost 50\% reduction in transduction rates compared to the parental vector controls (Figures 4(a) and 4(b)). One point to note is that the different promoters directed the eGFP transgene expression in the vectors. In this regard, it is always inaccurate to compare the levels of transgene expression under control of the different promoters (SFFV U3 versus EF1- $\alpha$ ).

$\mathrm{FV}$ replication strategy differs in many aspects from that of orthoretroviruses with the structural proteins displaying 


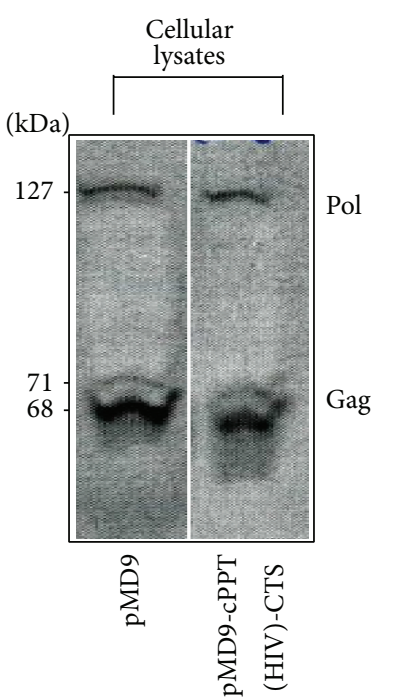

(a)

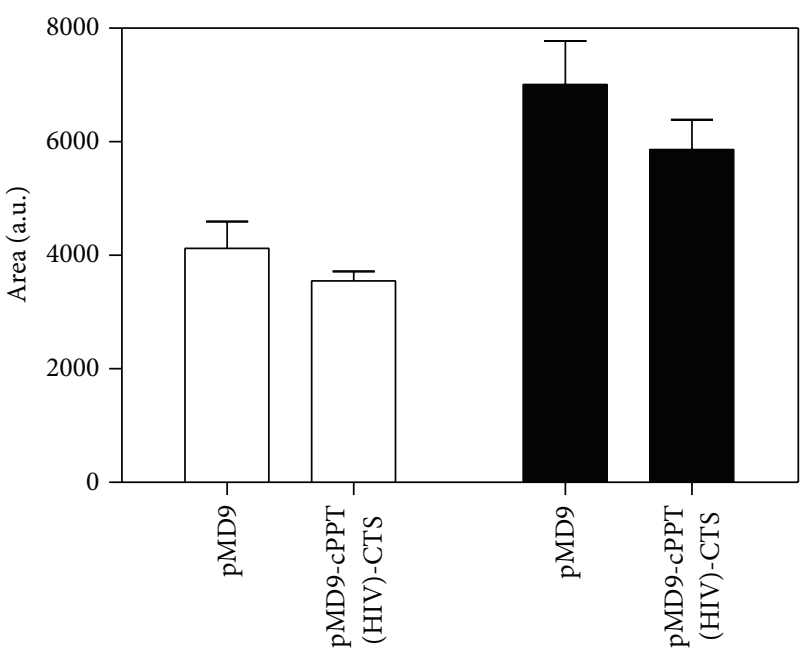

Pol

Gag

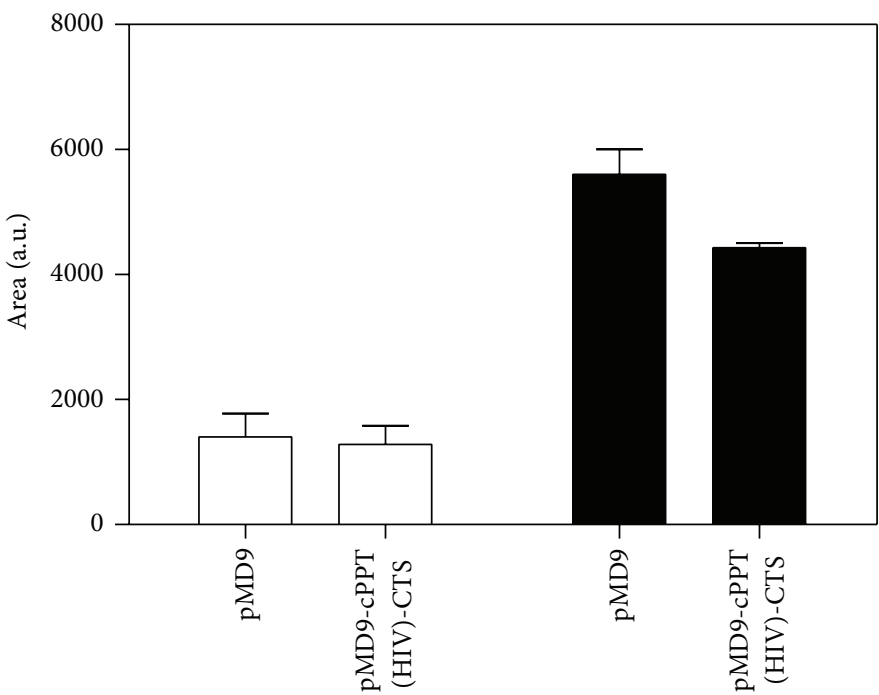

(c)

FIGURE 5: Analysis of pMD9 parental vector and its modification (pMD9-cPPT (HIV)-CTS). Detection of PFV proteins in HEK 293T cells (a) contransfected with the retroviral vectors was measured quantitatively for Gag/Pol (b) and Gag fractions (p71, p68) (c). The mean \pm SD values from three independent assays are shown. The area is measured in arbitrary units, which are abbreviated as a.u.

many unique functions not found for the corresponding orthoretroviral proteins. The FV structural proteins, Gag, Prt-RT, and Env are initially translated in polyprotein forms that are subsequently cleaved by cellular proteases (Gag and Prt-RT proteins), while Env polyprotein is cleaved by viral protease [15]. Interestingly, the protein analysis of the pMD9cPPT (HIV)-CTS plasmid compared to its parental form indicated that the A549 transduction for the modified vector was reduced when judged by the Gag/Pol decrease in the HEK 293T cellular lysates (Figures 5(a) and 5(b)). However, this was offset by a significant increase in the capacity to encapsidate Gag and Pol, producing a large pool of defective virus-like particles (Figures 6(a) and 6(b)).

The organization of Gag matrix protein into MA (p17 matrix), CA, (capsid p24), and NC (p6, nucleocapsid) with distinct cleavage sites observed in HIV-1 is absent in FVs. The only processing of FV Gag observed in the course of FV particle morphogenesis in vivo occurs at the $\mathrm{C}$ terminus of the molecule, removing a $3 \mathrm{kDa}$ peptide $(\mathrm{p} 3)$ and producing a shortened protein of $68 \mathrm{kDa}$. However, three internal secondary cleavage sites have been characterized in vitro that seem to be important during steps of the FV replication 

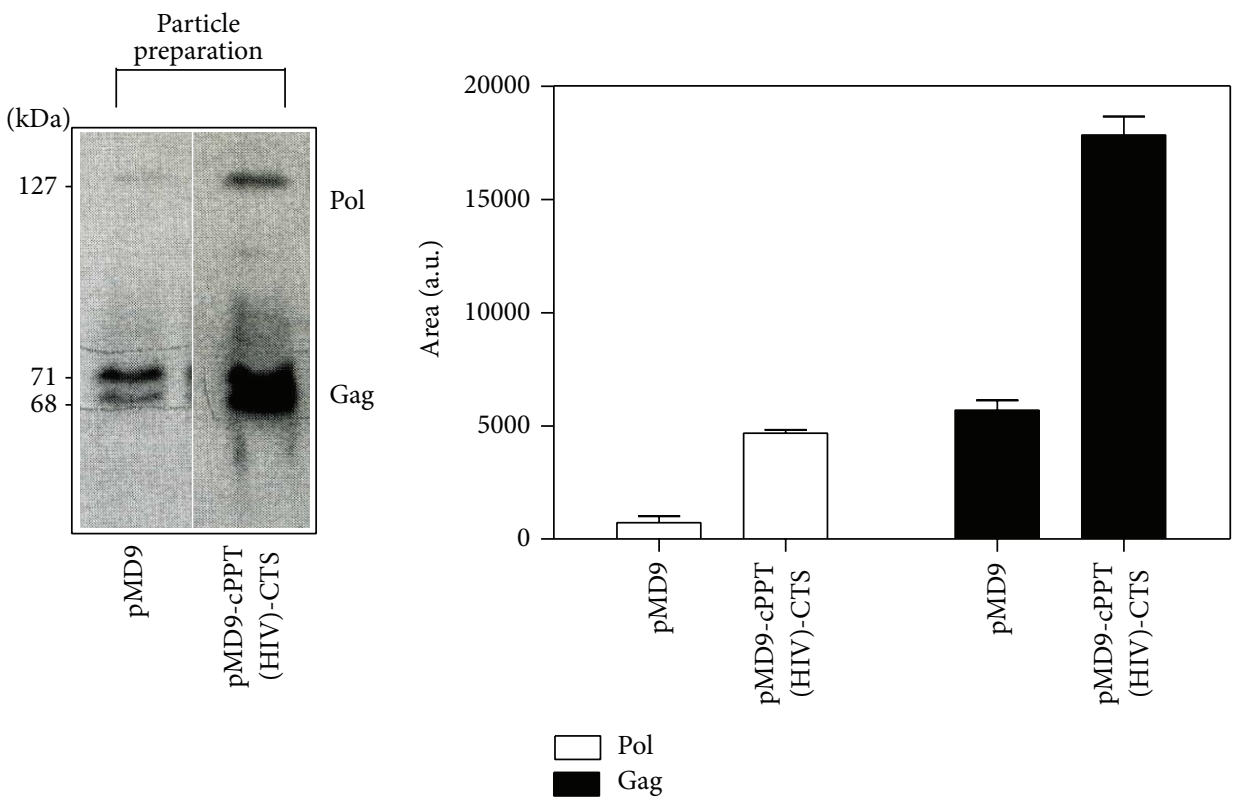

(a)

(b)

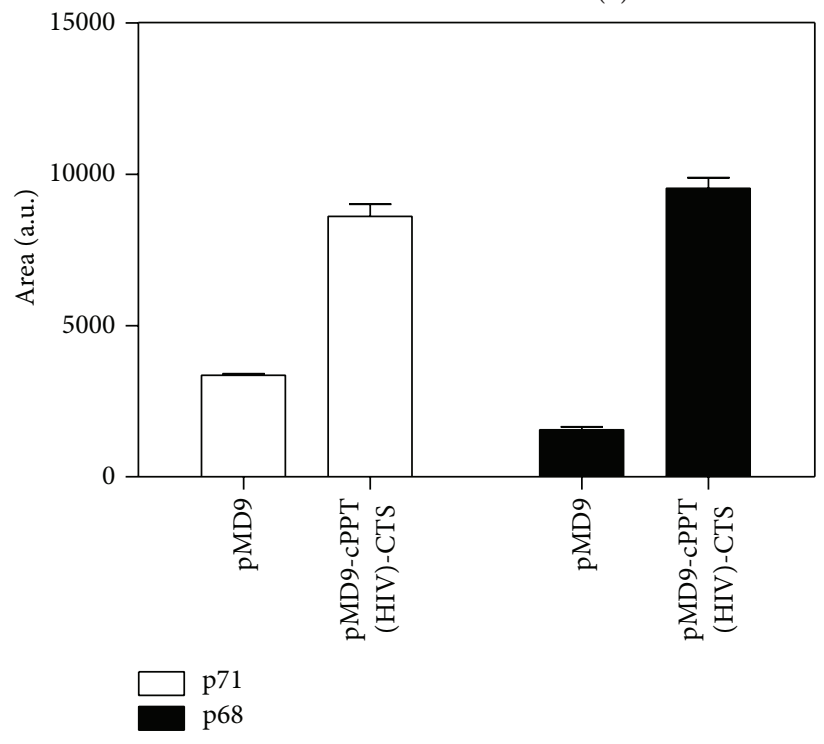

(c)

FIGURE 6: Analysis of pMD9 parental vector and its modification (pMD9-cPPT (HIV)-CTS). Detection of PFV proteins in partially purified viral particles produced by HEK 293T cells (a) contransfected with the retroviral vectors was measured quantitatively for Gag/Pol (b) and Gag fractions (p71, p68) (c). The mean \pm SD values from three independent assays are shown. The area is measured in arbitrary units, which are abbreviated as a.u.

cycle upon entry into target cells [15]. Thereby, in the 293T cellular lysates, the domination of the cleaved versions of Gag (p68) for either the pMD9 or pMD9-cPPT (HIV)-CTS constructs (Figure 5(c)) was observed. However, the protein analysis of the particle preparation revealed the prevalence of an uncleaved Gag fraction (p71) for pMD9, indicating the incomplete proteolytic cleavage of the FV capsid protein. The same fractions were detected in equal amounts in partially purified particles produced by HEK 293T cells and cotransfected with the modified plasmid (Figure 6(c)).

To assess the viral transduction dynamics and viral titre, the logistic dose-response function was transformed according to (1) and (2), to model the experimentally determined efficiency of the retroviral replication as percentage of eGFP cells observed in the A549 cells. Both parameters demonstrated a correlation to the aforementioned data shown in Figure 4 indicating some decrease of $f(x)_{\mathrm{td}}$ and $f(x)_{\mathrm{vt}}$ in dividing cells (Figures 7(a), 7(b), 8(a), and 8(b)). Similarly, the FV inability to transduce at a significant extent the growtharrested cells provided very low $f(x)_{\mathrm{td}}$ and $f(x)_{\mathrm{vt}}$ values (Figures 7(c) and 8(c)).

Overall, the results might be in conflict with a published report claiming that simian FV vectors can efficiently transduce aphidicolin-treated cells [40]. While the results cannot rule out strain-specific differences in the vector systems used, it is highly likely that simian FV vectors require mitosis for 


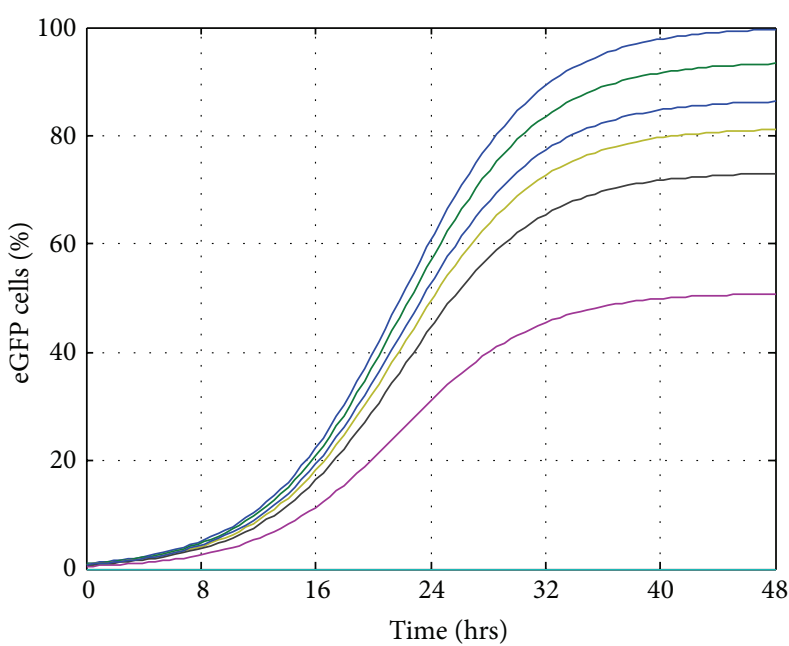

— pWPXL
- pMD9
— pMD9-(w/oEnv)
pcDNA

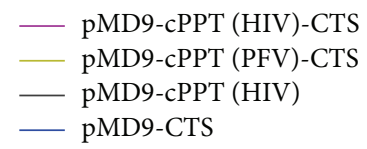

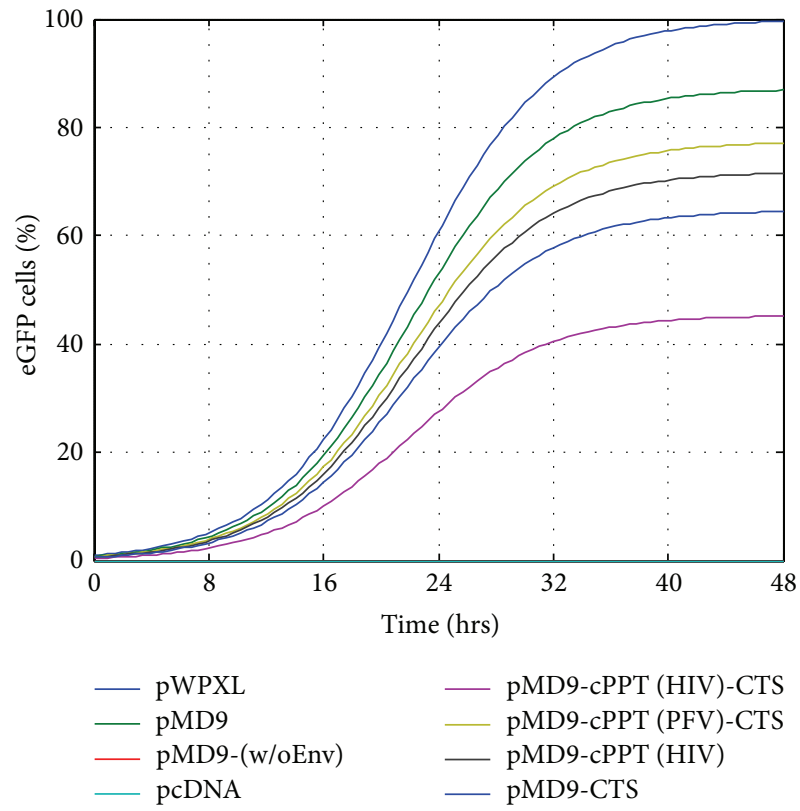

(b)

(a)

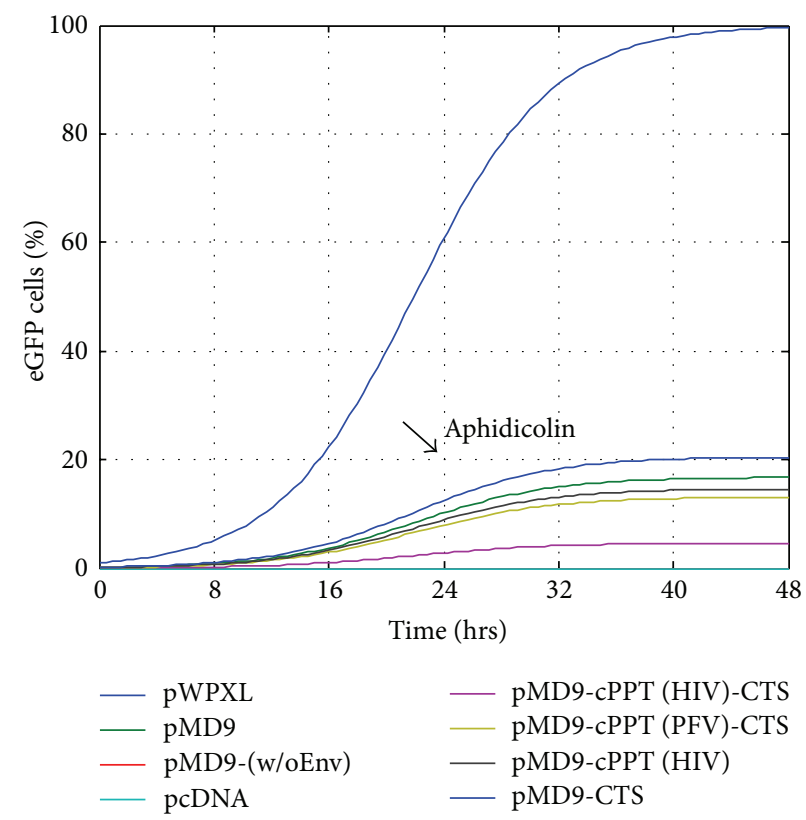

(c)

Figure 7: Dynamic $f(x)_{\text {td }}$ function: logistic dose-response curve to predict and model viral infection cycle of retroviral replication efficiency in the A549 cells. The pMD9-based plasmids were tested to efficiently transduce dividing and growth-arrested cells $\left(\mathrm{G}_{1} / \mathrm{S}\right.$ phase of cell cycle). Three conditions were analysed in the experiment: control (a); DMSO (b); aphidicolin (c).

their efficient transduction. Moreover, they require a breakdown of the nuclear envelope for a successful nuclear entry $[39,41]$. Lentiviral vectors also enter the nucleus using specific nuclear localization signals $[8,42]$.

It is more complicated that after viral disassembly in a cytoplasm some retroviral NLS sequences are recognized by host-cell import factors such as transportins that mediate nuclear targeting of PICs via the nuclear pore complex [7]. Several similar sequences are present in HIV-1, most significantly in the virus integrase $[8,43]$. Foamy viral Gag and Pol proteins also include NLS sequences [38], but they were recently shown to be nonfunctional [44].

Like HIV-1, PIC formation is also present in FVs before the transport of double-stranded cDNA of the virus to the cellular chromatin. Therefore, it is an essential part of replication of FVs [45]. However, the lower transduction efficiency of FV vectors in growth-arrested cells, in comparison with lentiviral forms, could be due to the fact that the foamy viral NLSs 


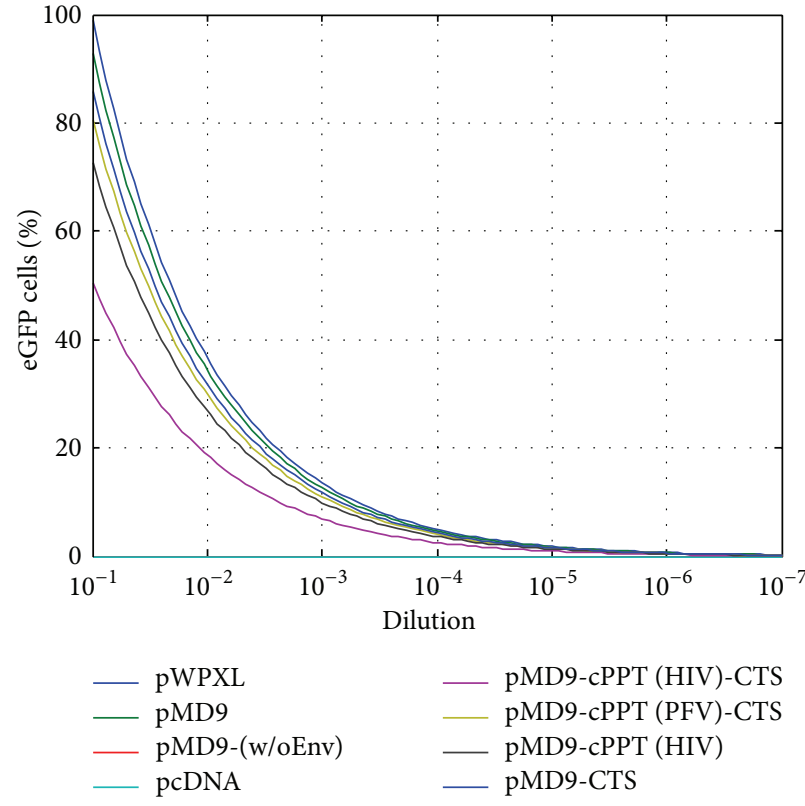

(a)

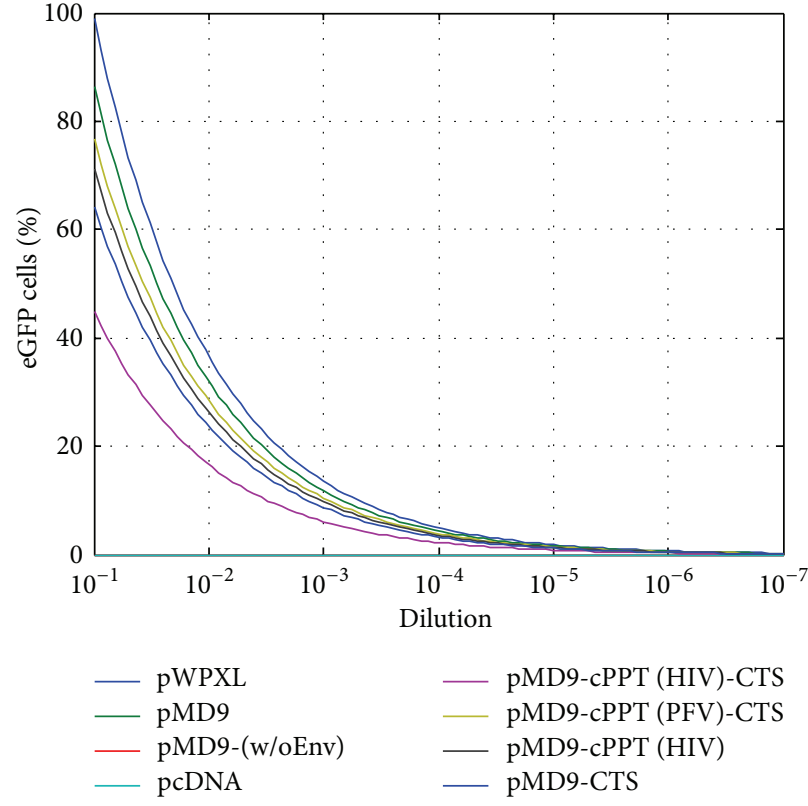

(b)

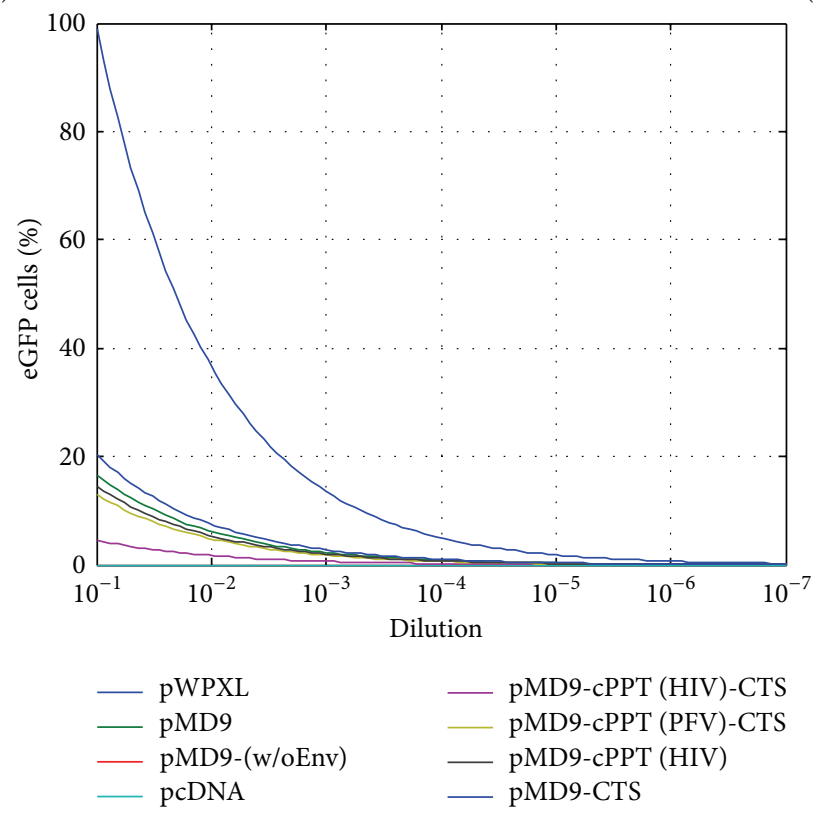

(c)

FIGURE 8: Dynamic $f(x)_{\mathrm{vt}}$ function: logistic dose-response curve to predict and model the viral titre. The pMD9-based vectors were tested to efficiently transduce dividing and growth-arrested cells $\left(\mathrm{G}_{1} / \mathrm{S}\right.$ phase of cell cycle). Three conditions were analysed in the experiment: control (a); DMSO (b); aphidicolin (c).

are being partially occluded in PIC [46], showing that PFV generates 2-LTR circles in nondividing cells. However, foamy virus vector preparations already contain 2-LTR circles, so their presence is not useful for monitoring PFV DNA entry into the nucleus although it is still possible that there are further functional blocks for successful PFV integration into a host genome after the nuclear translocation of its DNA.

In addition, some retroviruses (HIV-1) have a tendency to package some cellular proteins nonspecifically, and DNA ligase activity has been previously demonstrated for viral particles [47]. Therefore, these steps might also take place in intracellular or extracellular FV particles that contain cDNA molecules. Some studies even detected additional FV LTR circles by PCR in aphidicolin-arrested but not serum-deprived cultures [46]. There is a possibility that FV vectors use distinct mechanisms for nuclear import, as both the viral genome and Gag proteins accumulate near the centrosome/MTOC and wait for cell division. They then disassemble, releasing PIC [46].

The presence of cPPT, that serves as a primer for plusstrand synthesis to produce the HIV-1 "flap" element, has not been reported so far for FVs. But plus-strand synthesis that 
ultimately leads to the double-stranded cDNA, the molecular moiety that actually integrates into the host chromatin is a universal feature of all retroviruses including spumaviruses, the subfamily of FVs. The mechanism of formation of ds cDNA in FV might have a different mechanism.

Taken all together, the cell cycle dependences of foamy virus infection have demonstrated that vectors based on these viral genomes are not sufficient for specific targeting of nondividing cells. Nonetheless, the neurotropism of foamy viruses is worth testing in animal models. Further studies will be needed to directly compare foamy viral and lentiviral vectors in preclinical gene therapy experiments and define the nature of the stable FV vector transduction intermediate in quiescent cells.

\section{Conclusion}

In the experiments, modified foamy viral vectors showed a reduction in transduction rates of dividing, especially $G_{1} / S$ arrested A549 cells in comparison to lentiviral forms. The findings have confirmed that mitosis is a critical phase in the cell cycle for FV transduction, which was previously observed by Bieniasz and coauthors as an absence of the FV protein expression in $\mathrm{G}_{1} / \mathrm{S}$ - and $\mathrm{G}_{2}$-arrested cells [22].

From the data, it is clear that foamy viruses are not able to infect nondividing cells efficiently most likely because of lower integration efficiency compared to lentiviruses unless cells are undergoing mitosis. The results are in accordance with the previous findings of Trobridge and Russell but are contrary to the observations published by Mergia and coauthors $[32,40]$. Hence, the current study leads to the fact that foamy viral vectors could be further improved to be effective in gene therapy to target nondividing cells.

It is shown how foamy viral vectors can infect the A549 cells in dividing and growth-arrested states; cell-type specific experiments and molecular cloning strategies were included to clearly demonstrate that HIV-1 cPPT cannot be substituted for PFV cPPT without loss of functionality. This might be because the cognate reverse transcription enzyme is required for recognition of cPPT and CTS sequences. Furthermore, validated simulation data and curves were provided for the dynamic FV replication potential.

\section{Conflict of Interests}

The authors do not have any conflict of interests regarding the publication of this paper.

\section{Acknowledgments}

Special thanks are extended to Professor George Vassilopoulos from the University of Thessaly Medical School, Dr. Jayashree S. Nandi from the Albert Einstein College of Medicine, and Anna Poon from the City College of New York for their assistance in the paper's writing. The authors are also grateful to Drs. Otto Erlwein and Nathan Sweeney from the Imperial College of Science, Technology and Medicine for their valuable suggestions. They also thank Interdisziplinäres
Zentrum für Klinische Forschung (IZKF) for funding. Some data from this study were used in the doctoral thesis titled "Molecular modelling and simulation of retroviral proteins and nanobiocomposites" by Sergey Shityakov. This publication was financially supported by Deutsche Forschungsgemeinschaft (DFG) and the University of Würzburg in the funding program for Open Access Publishing.

\section{References}

[1] P. Charneau and F. Clavel, "A single-stranded gap in human immunodeficiency virus unintegrated linear DNA defined by a central copy of the polypurine tract," Journal of Virology, vol. 65, no. 5, pp. 2415-2421, 1991.

[2] P. Charneau, M. Alizon, and F. Clavel, "A second origin of DNA plus-strand synthesis is required for optimal human immunodeficiency virus replication," Journal of Virology, vol. 66, no. 5, pp. 2814-2820, 1992.

[3] P. Charneau, G. Mirambeau, P. Roux, S. Paulous, H. Buc, and F. Clavel, "HIV-1 reverse transcription. A termination step at the center of the genome," Journal of Molecular Biology, vol. 241, no. 5, pp. 651-662, 1994.

[4] M. Lavigne, P. Roux, H. Buc, and F. Schaeffer, "DNA curvature controls termination of plus strand DNA synthesis at the centre of HIV-1 genome," Journal of Molecular Biology, vol. 266, no. 3, pp. 507-524, 1997.

[5] B. Bowerman, P. O. Brown, J. M. Bishop, and H. E. Varmus, "A nucleoprotein complex mediates the integration of retroviral DNA," Genes \& Development, vol. 3, no. 4, pp. 469-478, 1989.

[6] P. O. Brown, B. Bowerman, H. E. Varmus, and J. M. Bishop, "Retroviral integration: structure of the initial covalent product and its precursor, and a role for the viral IN protein," Proceedings of the National Academy of Sciences of the United States of America, vol. 86, no. 8, pp. 2525-2529, 1989.

[7] S. Shityakov, A. Rethwilm, and T. Dandekar, "Structural and docking analysis of HIV-1 integrase and transportin-SR2 interaction: is this a more general and specific route for retroviral nuclear import and its regulation?" Online Journal of Bioinformatics, vol. 11, no. 1, pp. 19-33, 2010.

[8] M. I. Bukrinsky, S. Haggerty, M. P. Dempsey et al., "A nuclear localization signal within HIV-1 matrix protein that governs infection of non-dividing cells," Nature, vol. 365, no. 6447, pp. 666-669, 1993.

[9] U. Von Schwedler, R. S. Kornbluth, and D. Trono, “The nuclear localization signal of the matrix protein of human immunodeficiency virus type 1 allows the establishment of infection in macrophages and quiescent T lymphocytes," Proceedings of the National Academy of Sciences of the United States of America, vol. 91, no. 15, pp. 6992-6996, 1994.

[10] J. J. Hooks and C. J. Gibbs Jr., "The foamy viruses," Bacteriological Reviews, vol. 39, no. 3, pp. 169-185, 1975.

[11] P. Brown, G. Nemo, and D. C. Gajdusek, "Human foamy virus: further characterization, seroepidemiology, and relationship to chimpanzee foamy viruses," Journal of Infectious Diseases, vol. 137, no. 4, pp. 421-427, 1978.

[12] G. J. Nemo, P. W. Brown, C. J. Gibbs Jr., and D. C. Gajdusek, "Antigenic relationship of human foamy virus to the simian foamy viruses," Infection and Immunity, vol. 20, no. 1, pp. 69-72, 1978.

[13] O. Herchenroder, R. Renne, D. Loncar et al., "Isolation, cloning, and sequencing of simian foamy viruses from chimpanzees 
(SFVcpz): high homology to human foamy virus (HFV)," Virology, vol. 201, no. 2, pp. 187-199, 1994.

[14] M. Schweizer and D. Neumann-Haefelin, "Phylogenetic analysis of primate foamy viruses by comparison of pol sequences," Virology, vol. 207, no. 2, pp. 577-582, 1995.

[15] O. Delelis, J. Lehmann-Che, and A. Saïb, "Foamy viruses-a world apart," Current Opinion in Microbiology, vol. 7, no. 4, pp. 400-406, 2004.

[16] J. A. Mikovits, P. M. Hoffman, A. Rethwilm, and F. W. Ruscetti, "In vitro infection of primary and retrovirus-infected human leukocytes by human foamy virus," Journal of Virology, vol. 70, no. 5, pp. 2774-2780, 1996.

[17] K. Stirnnagel, D. Lüftenegger, A. Stange et al., "Analysis of prototype foamy virus particle-host cell interaction with autofluorescent retroviral particles," Retrovirology, vol. 7, article 45, 2010.

[18] C. D. Meiering and M. L. Linial, "Historical perspective of foamy virus epidemiology and infection," Clinical Microbiology Reviews, vol. 14, no. 1, pp. 165-176, 2001.

[19] H. E. Huber and C. C. Richardson, "Processing of the primer for plus strand DNA synthesis by human immunodeficiency virus 1 reverse transcriptase," The Journal of Biological Chemistry, vol. 265, no. 18, pp. 10565-10573, 1990.

[20] G. Luo, L. Sharmeen, and J. Taylor, "Specificities involved in the initiation of retroviral plus-strand DNA," Journal of Virology, vol. 64 , no. 2, pp. 592-597, 1990.

[21] K. A. Pullen, A. J. Rattray, and J. J. Champoux, "The sequence features important for plus strand priming by human immunodeficiency virus type 1 reverse transcriptase," The Journal of Biological Chemistry, vol. 268, no. 9, pp. 6221-6227, 1993.

[22] P. D. Bieniasz, O. Erlwein, A. Aguzzi, A. Rethwilm, and M. O. McClure, "Gene transfer using replication-defective human foamy virus vectors," Virology, vol. 235, no. 1, pp. 65-72, 1997.

[23] M. Heinkelein, M. Dressler, G. Jármy et al., "Improved primate foamy virus vectors and packaging constructs," Journal of Virology, vol. 76, no. 8, pp. 3774-3783, 2002.

[24] D. Lindemann and A. Rethwilm, "Foamy virus biology and its application for vector development," Viruses, vol. 3, no. 5, pp. 561-585, 2011.

[25] M. Linial, "Why aren't foamy viruses pathogenic?" Trends in Microbiology, vol. 8, no. 6, pp. 284-289, 2000.

[26] A. Mergia, N. J. Leung, and J. Blackwell, "Cell tropism of the simian foamy virus type 1 (SFV-1)," Journal of Medical Primatology, vol. 25, no. 1, pp. 2-7, 1996.

[27] D. W. Russell and A. D. Miller, "Foamy virus vectors," Journal of Virology, vol. 70, no. 1, pp. 217-222, 1996.

[28] C. L. Hill, P. D. Bieniasz, and M. O. McClure, "Properties of human foamy virus relevant to its development as a vector for gene therapy," Journal of General Virology, vol. 80, no. 8, pp. 2003-2009, 1999.

[29] G. Vassilopoulos, G. Trobridge, N. C. Josephson, and D. W. Russell, "Gene transfer into murine hematopoietic stem cells with helper-free foamy virus vectors," Blood, vol. 98, no. 3, pp. 604-609, 2001.

[30] G. Trobridge, N. Josephson, G. Vassilopoulos, J. Mac, and D. W. Russell, "Improved foamy virus vectors with minimal viral sequences," Molecular Therapy, vol. 6, no. 3, pp. 321-328, 2002.

[31] G. D. Trobridge and D. W. Russell, "Helper-free foamy virus vectors," Human Gene Therapy, vol. 9, no. 17, pp. 2517-2525, 1998.

[32] G. Trobridge and D. W. Russell, "Cell cycle requirements for transduction by foamy virus vectors compared to those of oncovirus and lentivirus vectors," Journal of Virology, vol. 78, no. 5, pp. 2327-2335, 2004.

[33] J. Sambrook and D. W. Russell, Molecular Cloning: A Laboratory Manual, Cold Spring Harbor Laboratory, New York, NY, USA, 2001.

[34] R. B. DuBridge, P. Tang, and H. C. Hsia, "Analysis of mutation in human cells by using an Epstein-Barr virus shuttle system," Molecular and Cellular Biology, vol. 7, no. 1, pp. 379-387, 1987.

[35] A. Stange, I. Mannigel, K. Peters et al., "Characterization of prototype foamy virus Gag late assembly domain motifs and their role in particle egress and infectivity," Journal of Virology, vol. 79, no. 9, pp. 5466-5476, 2005.

[36] K. Gärtner, T. Wiktorowicz, J. Park, A. Mergia, A. Rethwilm, and C. Scheller, "Accuracy estimation of foamy virus genome copying," Retrovirology, vol. 6, article 32, 2009.

[37] K. Peters, T. Wiktorowicz, M. Heinkelein, and A. Rethwilm, "RNA and protein requirements for incorporation of the Pol protein into foamy virus particles," Journal of Virology, vol. 79, no. 11, pp. 7005-7013, 2005.

[38] H. Imrich, M. Heinkelein, O. Herchenroder, and A. Rethwilm, "Primate foamy virus Pol proteins are imported into the nucleus," Journal of General Virology, vol. 81, no. 12, pp. 29412947, 2000.

[39] T. Roe, T. C. Reynolds, G. Yu, and P. O. Brown, "Integration of murine leukemia virus DNA depends on mitosis," The EMBO Journal, vol. 12, no. 5, pp. 2099-2108, 1993.

[40] A. Mergia, S. Chari, D. L. Kolson, M. M. Goodenow, and T. Ciccarone, "The efficiency of simian foamy virus vector type-1 (SFV-1) in nondividing cells and in human PBLs," Virology, vol. 280, no. 2, pp. 243-252, 2001.

[41] D. Lindemann, I. Steffen, and S. Pöhlmann, "Cellular entry of retroviruses," in Viral Entry into Host Cells, vol. 790 of Advances in Experimental Medicine and Biology, pp. 128-149, 2013.

[42] S. Popov, M. Rexach, G. Zybarth et al., "Viral protein R regulates nuclear import of the HIV-1 pre-integration complex," The EMBO Journal, vol. 17, no. 4, pp. 909-917, 1998.

[43] M. Bouyac-Bertoia, J. D. Dvorin, R. A. M. Fouchier et al., "HIV1 infection requires a functional integrase NLS," Molecular Cell, vol. 7, no. 5, pp. 1025-1035, 2001.

[44] E. Müllers, K. Stirnnagel, S. Kaulfuss, and D. Lindemann, "Prototype foamy virus gag nuclear localization: a novel pathway among retroviruses," Journal of Virology, vol. 85, no. 18, pp. 9276-9285, 2011.

[45] U. Berka, M. V. Hamann, and D. Lindemann, "Early events in foamy virus-host interaction and intracellular trafficking," Viruses, vol. 5, no. 4, pp. 1055-1074, 2013.

[46] A. Saïb, F. Puvion-Dutilleul, M. Schmid, J. Périès, and H. de Thé, "Nuclear targeting of incoming human foamy virus Gag proteins involves a centriolar step," Journal of Virology, vol. 71, no. 2, pp. 1155-1161, 1997.

[47] H. M. Temin and D. Baltimore, "RNA-directed DNA synthesis and RNA tumor viruses," Advances in Virus Research, vol. 17, no. C, pp. 129-186, 1972. 

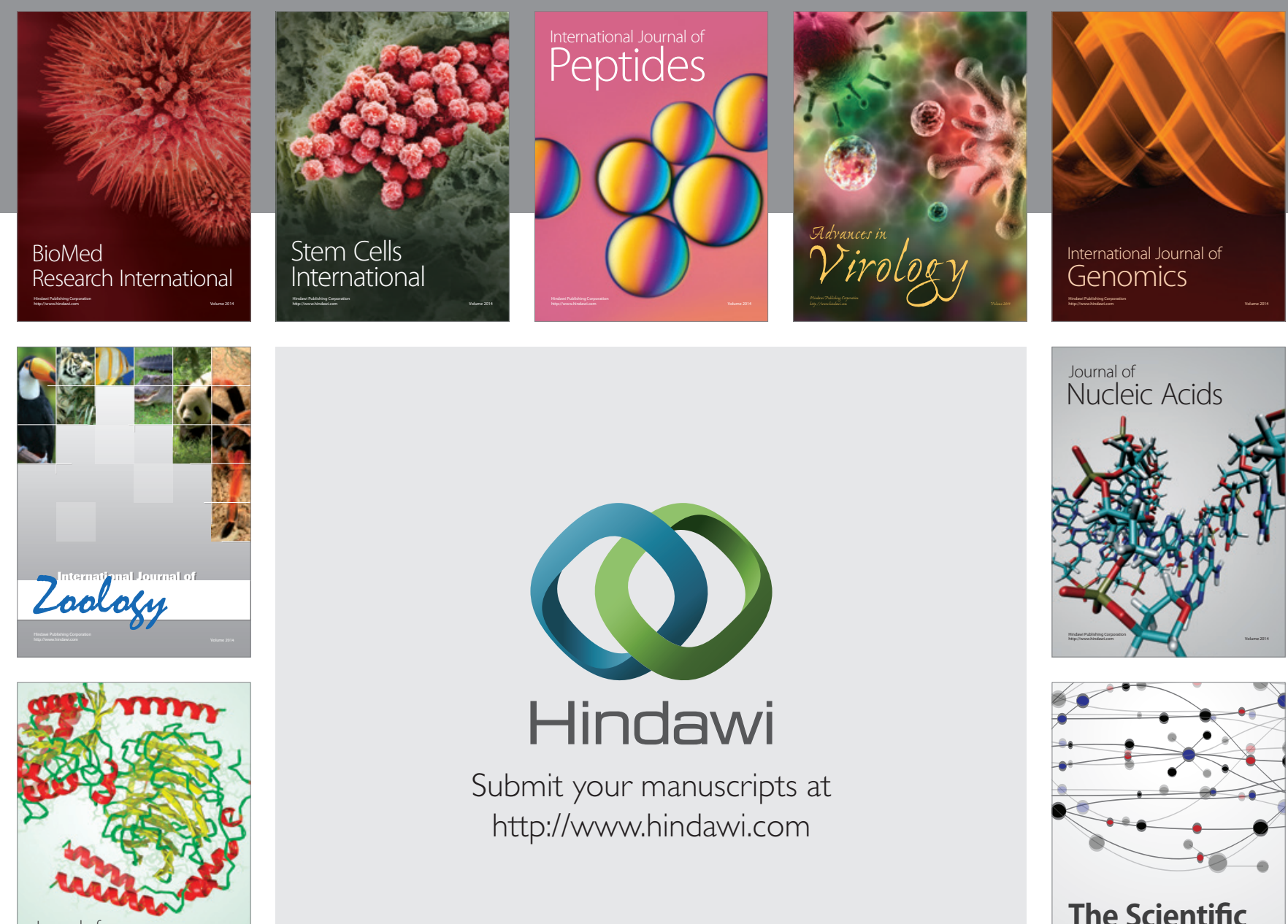

Submit your manuscripts at

http://www.hindawi.com

Journal of
Signal Transduction
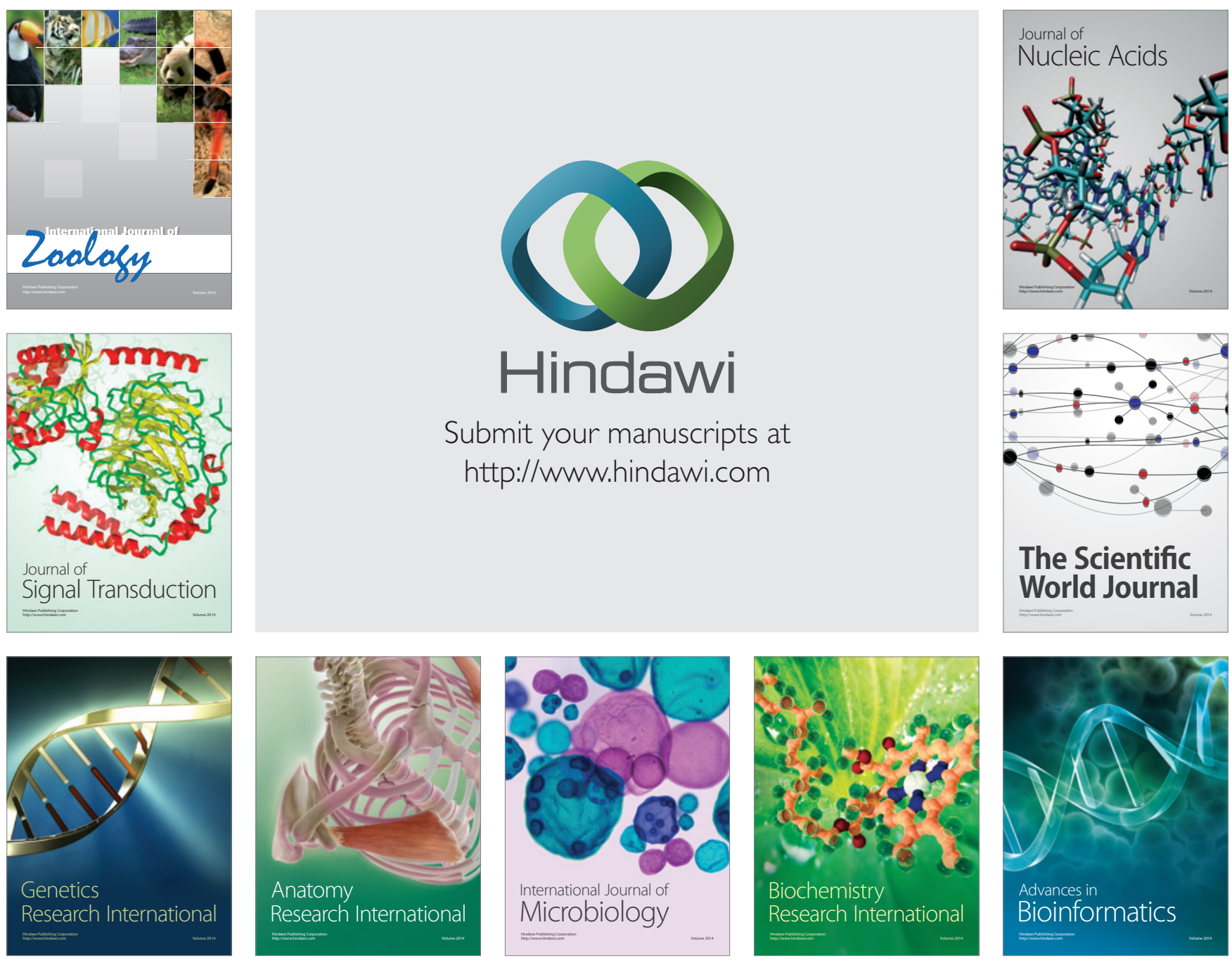

The Scientific World Journal
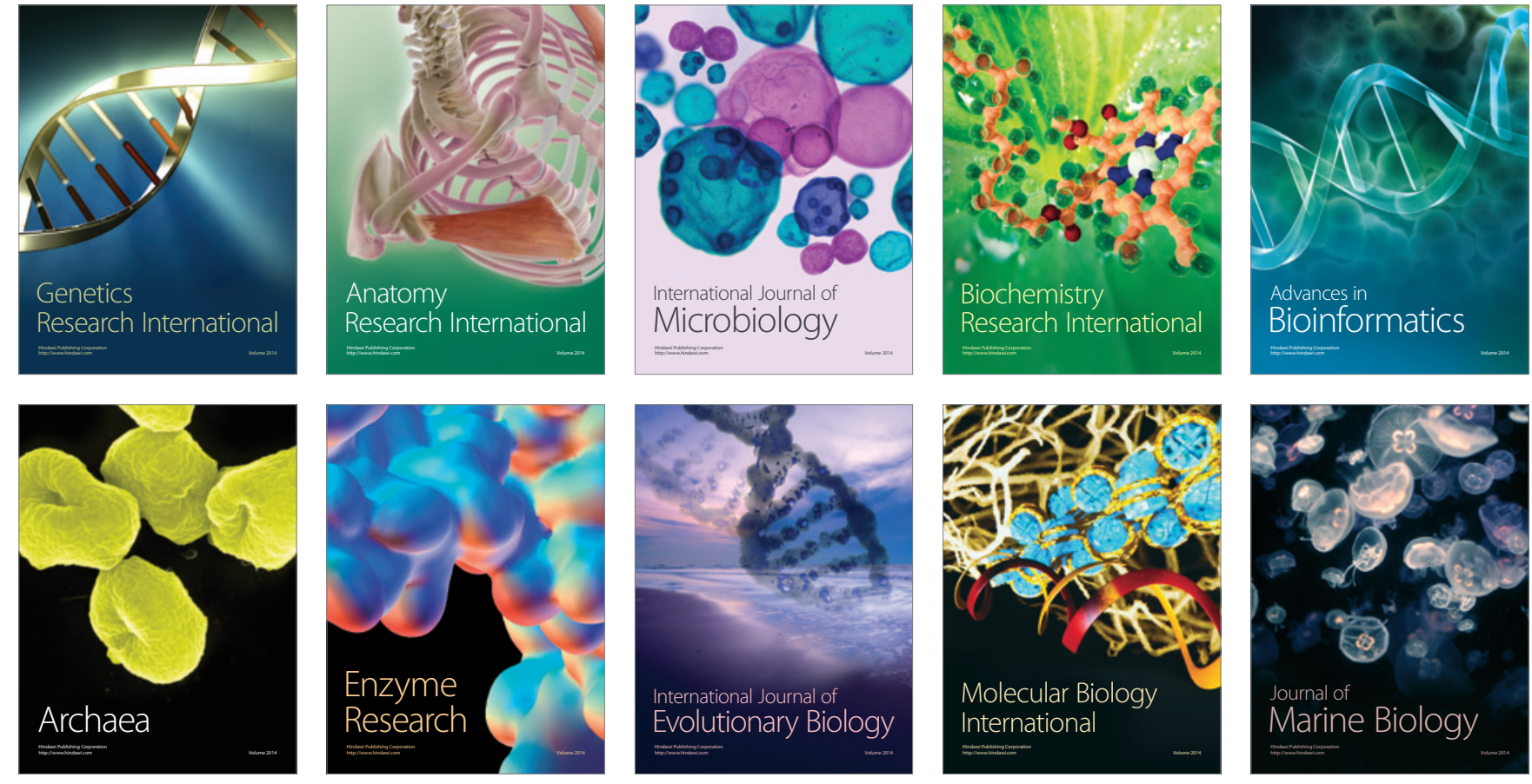